\title{
Bilateral Vestibular Hypofunction: Challenges in Establishing the Diagnosis in Adults
}

\author{
Raymond van de Berga, ${ }^{a}$ Mark van Tilburg ${ }^{a} \quad$ Herman Kingma $^{a}$ b \\ ${ }^{a}$ Division of Balance Disorders, Department of Otorhinolaryngology and Head and \\ Neck Surgery, Faculty of Health Medicine and Life Sciences, School for Mental Health and \\ Neuroscience, Maastricht University Medical Center, Maastricht, The Netherlands; \\ ${ }^{b}$ Faculty of Physics, Tomsk State University, Tomsk, Russian Federation
}

\section{Key Words}

Bilateral vestibular hypofunction - Bilateral vestibulopathy - Bilateral vestibular areflexia .

Bilateral vestibular loss - Vestibular implant - Vestibular prosthesis - Head impulse test .

Caloric test $\cdot$ Rotatory chair tests . Vestibulo-ocular reflex

\begin{abstract}
Bilateral vestibular hypofunction (BVH) probably represents a heterogeneous disorder with different types of clinical pictures, with and without vertigo. In spite of increasingly sophisticated electrophysiological testing, still many challenges are met when establishing a diagnosis of BVH. Here, we review the main challenges, which are a reflection of its often difficult clinical presentation and the lack of diagnostic standards regarding the implementation and interpretation of vestibular tests. These challenges show that there is an urgent need for standardization. The resulting decisions should be used for the development of uniform diagnostic criteria for BVH, which are, at present, not yet available.

(C) 2015 S. Karger AG, Basel
\end{abstract}

\section{Introduction}

Vestibular Disorders and Diagnosis

Vertigo and dizziness are frequently encountered in outpatient practices, affecting up to $36 \%$ of the population [1]. However, even the more common vestibular diagnoses such as benign paroxysmal positional vertigo and vestibular migraine are often under- or misdiag- 
Table 1. Etiologies of BVH [12, $18-44]$

\begin{tabular}{ll}
\hline Idiopathic (51\%) & - \\
\hline $\begin{array}{l}\text { Toxic/metabolic } \\
\text { (13-21\%) }\end{array}$ & $\begin{array}{l}\text { Antibiotics, furosemide, cisplatin, aspirin, alcohol, vitamin B } \text { If }_{\text {deficiency, folate }} \\
\text { anti-inflammatory drug plus penicillin }\end{array}$ \\
\hline Infectious (3.8-12\%) & $\begin{array}{l}\text { Meningitis/encephalitis/cerebellitis, lues, Behçet's disease, Borrelia infection, } \\
\text { herpes simplex virus infection, bilateral neuritis }\end{array}$ \\
\hline Autoimmune (10\%) & $\begin{array}{l}\text { Cogan's syndrome, Susac's syndrome, sarcoidosis, Wegener's granulomatosis, } \\
\text { Sjögren's syndrome, colitis, celiac disease, polyarteritis nodosa, antiphospholipid } \\
\text { syndrome, other systemic diseases }\end{array}$ \\
\hline Neurodegenerative & $\begin{array}{l}\text { CANVAS, superficial siderosis, episodic ataxia, multiple system atrophy, } \\
\text { polyneuropathy, SCA3, SCA6, hereditary sensory and autonomic neuropathy type } \\
\text { IV, other ataxias }\end{array}$ \\
\hline Genetic & DFNA-9, DFNA-11, DFNA-15, DFNB-4, mutation chromosome 5q, 6q, 11q, 22q \\
\hline Vascular & Supra- or infratentorial lesions, vertebrobasilar dolichoectasia \\
\hline Neoplastic & $\begin{array}{l}\text { Bilateral vestibular schwannoma, neurofibromatosis type 2, metastasis of } \\
\text { lymphoma, malignant tumor }\end{array}$ \\
\hline Trauma & Head trauma, iatrogenic (e.g. bilateral cochlear implantation) \\
\hline Other ear pathology & Bilateral Menière's disease, otosclerosis, bilateral labyrinthitis, cholesteatoma \\
\hline
\end{tabular}

SCA = Spinocerebellar ataxia; CHARGE = coloboma, heart defects, atresia of the choanae, retardation of growth and development, genital and urinary abnormalities, ear abnormalities and/or hearing loss.

nosed [2]. The difficulty of making the right vestibular diagnosis is reflected in the fact that in some populations, more than one third of the patients with a vestibular disease consult more than one physician [3] - in some cases up to more than fifteen [4]. It is necessary to have a correct diagnosis, since an incorrect diagnosis of a vestibular disease may eventually result in increased health care utilization and chronicity [3].

Bilateral vestibular hypofunction (BVH), currently a less common vestibular diagnosis, is also often under- or misdiagnosed [5, 6]. It poses a diagnostic challenge [7]. Even in the literature, reported prevalence rates vary from 28 to 81 per 100,000 people [6, 8], and the percentages of BVH found in patients who underwent electronystagmography vary from 0.6 to $13.6 \%[5,9-11]$. This article will discuss the challenges and pitfalls a physician meets when diagnosing $\mathrm{BVH}$.

\section{What Is BVH?}

$\mathrm{BVH}$ is characterized by reduced or absent function of both vestibular organs, the vestibular nerves or a combination of both [12], which results in impairment or loss of the major functions of the vestibular organs: gaze stabilization, maintaining balance, postural control and spatial orientation [13]. The best-known symptoms are oscillopsia (blurred vision), chronic disequilibrium, postural instability and impaired spatial orientation [14-16]. Dandy [17] was the first to describe BVH in 1941, after performing a bilateral vestibular neurectomy for Menière's disease. Nowadays, this symptom complex is known to have many 
van de Berg et al.: Bilateral Vestibular Hypofunction: Challenges in Establishing the Diagnosis in Adults

causes, and BVH probably represents a functionally heterogeneous disorder with different combined or isolated deficits of the semicircular canals and/or otolith organs [18]. Most of the etiologies described are presented in table $1[12,18-44]$. However, its etiology still remains unclear in approximately $50 \%$ of all cases $[7,19]$.

\section{Challenges in Establishing a Diagnosis of BVH}

\section{Challenge One: Recognizing the Impact of BVH}

The impact of BVH on quality of life is still controversial, and the handicap is not always recognized $[8,21,45]$. Even the recent literature still reports on patients who underwent a bilateral vestibular neurectomy [46]. Although effects on different aspects of life are not as yet completely well defined, increasing evidence shows that BVH affects different aspects of life significantly $[6,8,46]$. Dizziness handicap inventory scores indicate that $44 \%$ of patients perceive the handicap due to BVH to be severe, while $41 \%$ view it as a moderate handicap [8]. Quality of life is not only decreased with regard to vision or ambulation dimensions, but also concerning functional and emotional dimensions [46]. Therefore, physical activity, social functioning and vitality decrease $[6,8] ; 55 \%$ of BVH patients miss school or work, and $75 \%$ are on disability. Besides an increased fear of falling, there is a 31-fold increased risk of falling [6]. It can be concluded that BVH not only substantially degrades quality of life but also imposes a socioeconomic burden on society [46].

If BVH occurs already early in life (e.g. via meningitis in childhood), it can impair the development of visual and somatosensory effectiveness in postural control due to its multimodal sensory interdependence [47]. Bilateral deficits in young children have been shown to lead to a delayed development of walking and postural control, delayed oculomotor control and learning difficulties $[47,48]$. Recognizing the impact of BVH emphasizes the need to make an accurate diagnosis and helps to understand the other symptoms associated with BVH $[47,49]$.

\section{Challenge Two: Recognizing the Symptoms of BVH}

Unlike when losing other sensory modalities such as vision, hearing or smell, symptoms of vestibular disorders are not always recognized by patients and physicians. Descriptions of the quality or type of dizziness have been found to be unclear, inconsistent and unreliable [50]. For BVH, this may be due to several reasons.

Firstly, due to the heterogeneous origin of the disease, four different types of clinical pictures have been described: (1) recurrent vertigo and BVH - patients have episodes of vertigo occurring over several years, followed by symptoms of vestibular hypofunction; (2) slowly progressive BVH - patients have a gradual onset of symptoms of vestibular hypofunction, without any episodes of vertigo; (3) rapidly progressive BVH - patients have a sudden onset or a rapid progression of symptoms of vestibular hypofunction, with or without episodes of vertigo (this can be seen e.g. in autoimmune disorders or as an effect of vestibulotoxic medication), and (4) BVH with other neurological deficits, such as cerebellar ataxia and neuropathy - symptoms of BVH are combined with neurological symptoms. These four types show a broad variety of clinical pictures, and it is clear that vertigo does not have to be a symptom of BVH. Also, hearing loss or tinnitus does not regularly accompany BVH. While patients with associated episodes of vertigo or hearing loss might seek medical attention early in their clinical course, other patients may have subtle and poorly recognized symptoms, leading to a delay in diagnosis [12, 19, 38, 41, 42].

Secondly, patients are often not aware that they have vestibular organs, until they start to fail. Vestibular controlled gaze stabilization and postural adjustments are reflexes (ves- 
tibulo-ocular, vestibulocollic and vestibulospinal) and go unnoticed. This is why vestibular sensation is not included in the five vernacular senses (hearing, vision, smell, taste and touch) [51]. Also, when the vestibular organs fail, nonlabyrinthine inputs to the vestibular nuclei are enhanced, partially filling the gap left by the failing residual labyrinthine input, with sensory substitution [52]. Accurately defining the symptoms of vestibular failure can become more difficult, especially since vertigo does not have to be the presenting symptom $[8,53]$. The main symptoms of BVH will now be explained in detail.

\section{Oscillopsia}

BVH leads to a reduced or absent vestibulo-ocular reflex [14]. Normally, gaze is stabilized by the vestibulo-ocular reflex, which compensates head rotations with equal eye rotations to the opposite direction. In BVH, the vestibulo-ocular reflex is deficient, which leads to the eyes moving along with the head, forcing the patient to make a catch-up saccade [54]. Failure of gaze stabilization leads to excessive motion of images of stationary objects upon the retina during head movements, impairing vision. The illusion of movement of the seen world is called oscillopsia [55]. BVH patients may complain of blurred vision during high-frequency head movements [56]. From our experience we noticed that not all patients are able to recognize that oscillopsia due to BVH only occurs during high-frequency head movements. Therefore, some patients first go to the ophthalmologist to have their vision checked. Unfortunately, visual acuity is often measured in a static condition (without any head movements) and not in a dynamic condition (with head movements). As a result, oscillopsia is often not detected by ophthalmologists. However, it can be detected by testing visual acuity in dynamic conditions, using the test for dynamic visual acuity (DVA) [57], which will be explained in the section Challenge Three: Quantifying BVH.

Not all patients with BVH complain of oscillopsia. Percentages of BVH patients suffering from oscillopsia vary from 25 to $86 \%$, and the degree of subjective complaints is not directly correlated with the severity of BVH as measured with objective tests $[5,7,10]$. Probably, mechanisms other than the vestibulo-ocular reflex may play a role in gaze stabilization during head movements [58].

Having these aspects in mind, oscillopsia can be difficult to acknowledge for patients as well as physicians. Moreover, not having oscillopsia does not rule out bilateral vestibulopathy.

\section{Imbalance}

BVH patients typically complain of unsteadiness or imbalance. Postural control and spatial orientation depend on vestibular, visual and proprioceptive inputs and on internal estimates based on motor efference. Due to failure of the vestibulospinal reflex in BVH, the multisensory process of postural control is hindered [5, 7, 21, 22, 59]. Especially fast corrections become impaired, and the accuracy of gravity detection decreases. This leads to unsteadiness or imbalance during locomotion and to an increase in falls. Compensation is partially attempted by relying more on the remaining inputs and estimates [60-62]. Therefore, unsteadiness or imbalance increases when the other inputs are challenged, e.g. while walking in the dark or on uneven surfaces $[6,19,22]$. Imbalance and unsteadiness can also occur merely as the result of high-frequency head movements, due to failure of gaze stabilization. BVH patients may report a sensation of the 'image lagging behind' when the head is turned fast (e.g. while taking care crossing the street), which can result in imbalance or unsteadiness [7]. Due to several factors, including the above-mentioned compensation and sometimes a slow progression of disease, unsteadiness or imbalance can be subtle in some patients, not being the key symptom of presentation. This can interfere with making the right diagnosis. 


\section{Visual Vertigo}

BVH patients rely more on other sensory inputs such as vision [62-64]. However, an increased visual dependence can result in symptoms of vertigo that are provoked or aggravated by specific visual contexts (e.g. supermarkets, movement of objects, driving, crowded places, scrolling down a computer screen, moving windshield wipers). This is called 'visual vertigo'. Patients suffering from visual vertigo have been shown to have abnormally large perceptual and postural responses to disorienting visual environments. This could reflect a difficulty in resolving a visually induced sensory conflict between visual and vestibuloproprioceptive inputs as a result of an increased visual dependence [13, 49, 62]. Unfortunately, many vestibular patients are diagnosed with a pure psychological disorder as a cause of these symptoms [65]. It is therefore important to recognize visual vertigo as a possible symptom of vestibulopathy.

\section{Cognitive Deficits}

BVH patients often suffer from cognitive deficits such as difficulty concentrating, being in a 'brain fog' or being more tired $[8,52,66]$. Since patients are continuously compensating and trying to avoid imbalance and falling, walking, for instance, is prioritized over secondary tasks such as cognitive ones. It is often said that a patient 'stops walking when talking' [67, 68]. Also spatial learning and memory are affected by loss of labyrinthine input, probably influenced by the hippocampus, which is subject to functional and structural changes [52, 69, 70]. A bilateral atrophy of the hippocampus was found in $17 \%$ of a BVH population, which correlated with spatial memory deficits $[71,72]$. The anterior hippocampus is also critically involved in emotional processes. Therefore, the hippocampus could be one of the main structures in which the cognitive and emotional effects of vestibular loss interact $[73,74]$. Other parts of the brain show changes in resting-state connectivity due to BVH, which may also account for the persistent deficits in visuospatial attention and spatial orientation as well as unsteadiness [63]. In other words, cognitive deficits can be related to vestibulopathy and should not be disregarded while taking the history of a patient.

\section{Psychological or Psychiatric Symptoms}

The chronic disequilibrium as well as difficulty performing routine daily activities as a result of BVH can have a psychological impact $[3,8,46]$. This is shown by a high prevalence of psychiatric symptoms among vertiginous patients [75, 76]. For instance, BVH patients more often report autonomic symptoms and somatic anxiety [49]. Besides those, psychiatric conditions such as depression could play a confounding role in the reported health status of patients [46]. In the chronic phase, it is mainly the psychiatric disorders which worsen the clinical picture along a more disabling and debilitating course, not the vertigo symptoms [76]. Taking these factors into account, BVH and psychological and psychiatric symptoms coexist and interfere with each other. Therefore, having a patient with mainly psychological or psychiatric symptoms in addition to dizziness does not directly exempt a physician from performing a vestibular workup.

Neurological Symptoms

BVH may be associated with neurological diseases, such as neurodegenerative diseases [e.g. spinocerebellar ataxia, multiple system atrophy, CANVAS (cerebellar ataxia, neuropathy and vestibular areflexia syndrome)], infectious diseases (e.g. meningitis, encephalitis, cerebellitis), neoplasms, vascular lesions, and others (table 1). Up to $39 \%$ of BVH patients may have a vestibular deficit combined with a neurological disorder $[12,20]$. In some cases, BVH may precede cerebellar ataxia. Often, BVH is underdiagnosed in cerebellar disorders, probably partly because cerebellar and vestibular disorders have overlapping signs and symptoms [22, 
van de Berg et al.: Bilateral Vestibular Hypofunction: Challenges in Establishing the Diagnosis in Adults

40]. Vestibular disorders may even be improperly diagnosed as a cerebellar syndrome [12]. Therefore, if imbalance is in excess of that expected for the severity of the neurological disorder, one should consider a coexisting BVH [23].

\section{Autonomic Symptoms}

With the vestibulosympathetic reflex, the peripheral vestibular system also has widespread effects on homeostatic regulatory physiology [77]. It has projections to sites involved in the central regulation of respiratory and cardiovascular activity (blood pressure and heart rate) as well as to sites that mediate the affective and emotional aspects of vestibuloautonomic function $[77,78]$. Therefore, BVH can, for instance, lead to orthostatic hypotension and to a disturbance in the association between vertigo and panic $[77,79]$.

\section{Challenge Three: Quantifying BVH}

For several reasons, BVH is a diagnostic challenge. Firstly, each test has its own limitations in terms of sensitivity, specificity, patient acceptance, costs and duration, and there is still no consensus about diagnostic criteria for BVH [7]. Secondly, since BVH probably represents a functionally heterogeneous disorder with different combined or isolated deficits of the vestibular system, different results from laboratory tests can be expected for different types of BVH $[18,80,81]$. Thirdly, the output parameters of laboratory tests such as the caloric test, rotatory chair tests and (video) head impulse testing [(V)HIT] show a considerable overlap between patients and healthy subjects [82]. Fourthly, clinical vestibular testing primarily measures reflexes [e.g. caloric test, rotatory chair tests, vestibular evoked myogenic potentials (VEMPs)], while perceptual thresholds are not yet routinely used to evaluate vestibular disorders [81]. However, they might be better correlated with complaints [81]. These tests could complement the standard vestibular testing battery used in clinical practice. The main examinations for determining BVH will now be discussed.

Neuro-Otological and Vestibular Physical Examination

A complete and thorough neuro-otological and vestibular examination is necessary to find any signs of vestibular hypofunction or any neurological diseases, particularly ataxia. During the neuro-otological assessment, one should pay especially close attention to the oculomotor examination, since abnormal oculomotor findings may be the only or first presenting central signs that may explain the vestibular symptoms [83]. The oculomotor examination is best performed before inducing the substantial head movements that are typical for some major components of the vestibular examination. The vestibular examination includes the Dix-Hallpike and the lateral roll test, positional testing, (V)HIT, the test for DVA, the visually enhanced vestibulo-ocular reflex test, fixation suppression, the Valsalva maneuver (straining against the closed glottis and blowing out against pinched nostrils), the head shake test, the vibration test, the hyperventilation test and the Romberg test on foam rubber or in tandem $[84,85]$. The Romberg test mainly diagnoses ataxia and is not specific for a vestibular loss, since it also detects cerebellar and proprioceptive impairment $[84,86]$. However, the sensitivity for detecting vestibular deficits increases when the patient stands on foam rubber [87]. The Romberg test on foam rubber has a sensitivity of up to $79 \%$ and a specificity of up to $80 \%$ for detecting both patients with unilateral and those with bilateral vestibular loss $[84,88]$. Although abnormalities in the other vestibular tests during physical examination can be found [85, 89], this review will not focus on them, since the main challenges for diagnosing and quantifying BVH are not encountered in these tests, except for HIT and the test for DVA; they will be discussed separately below. 
Head Impulse Testing

A brief, high-acceleration head 'impulse' can test vestibular function of all semicircular canals. Depending on the semicircular canal tested, the head is rotated in a different direction $[90,91]$. A corrective catch-up saccade is made in case of vestibular hypofunction. HIT can be performed with or without the use of a noninvasive video-oculography device (i.e. VHIT). This device consists of goggles that contain a high-speed infrared video camera that tracks eye movements and accelerometers that track head movements [92].

Although applying HIT may sound simple at first, some challenges are met when performing it. The first challenge is to adequately deliver the stimulus: it should be a highacceleration $\left(1,000-6,000^{\circ} / \mathrm{s}^{2}\right)$, rapid $\left(100-200^{\circ} / \mathrm{s}\right)$, low-amplitude $\left(10-20^{\circ}\right)$ head rotation. When using VHIT, one should pay attention by avoiding a loose strap, wrong calibration, pupil tracking loss, (mini-)blinks, touching the goggles, patient inattention and investigatorinduced bounce; if these are not avoided, they will result in artifacts [93].

The second challenge is not to be fooled by preprogrammed compensatory saccades ('covert saccades') that can be invisible to the naked eye of the examiner and can occur (not only) in BVH patients. Consequently, BVH may be missed [94]. A recent study by Strupp et al. indicated that HIT observed by the naked eye of experts is false negative for about $50 \%$ of the patients when compared to VHIT [pers. commun. H.K. with Michael Strupp]. This clearly supports the use of the VHIT device, which is able to track these saccades. Examples of normal and abnormal VHIT recordings with overt and covert saccades are presented in figure 1a-c.

The third challenge is to correctly interpret the traces. VHIT traces can have many artifacts, leading up to $42 \%$ of uninterpretable traces [93]. Besides these artifacts, eye movements in patients with a vestibular hypofunction can show patterns that challenge interpretations. Ideally, vestibulo-ocular reflex gain is calculated by peak eye velocity divided by peak head velocity [82]. However, artifacts and abnormal patterns distort the process of correct gain calculation, and commercially available software is not yet able to adequately compensate for it. An example of an eye movement pattern that interferes with gain calculation is presented in figure 2. In order not to miss a BVH, a physician should not yet solely rely on software processing for gain calculation, but should be trained in assessing the raw data and should be aware of the impact of deviant eye movement patterns and measurement artifacts [93].

The fourth challenge is to correctly interpret the end result. HIT provides a stimulus for measuring gain of the vestibulo-ocular reflex which is different from those used in other vestibular tests such as the rotatory chair tests or the caloric test; it includes many more highfrequency components than the rotatory chair tests and the caloric test. Differences in response to the caloric test versus the rotation tests versus HIT are especially pointing to this difference in frequency content. It has been shown that a bilateral vestibular loss can be measured with the caloric test, while the responses as measured with HIT are relatively preserved $[95,96]$. In other words, it is necessary to understand that the presence of a normal vestibulo-ocular reflex as measured with HIT does not rule out a vestibular deficiency.

Dynamic Visual Acuity

During head movements, efficient stabilization of the image on the retina is necessary to preserve visual acuity [8]. In BVH patients, gaze stabilization fails and can lead to significant deterioration in visual acuity during head movements [97, 98]. Visual acuity in dynamic conditions can be assessed by testing for DVA. DVA testing can be performed in many ways: the patient has to read letters from a visual acuity chart or a computer screen during active or passive, vertical or horizontal head movements, or while walking on a treadmill at different velocities [56, 99]. Passive high-angular-velocity movements $\left(150^{\circ} / \mathrm{s}\right)$ have been shown to be most useful for discrimination between healthy subjects and patients with a unilateral or bilateral vestibular loss. However, that study did not include DVA testing by walking on a 
van de Berg et al.: Bilateral Vestibular Hypofunction: Challenges in Establishing the Diagnosis in Adults
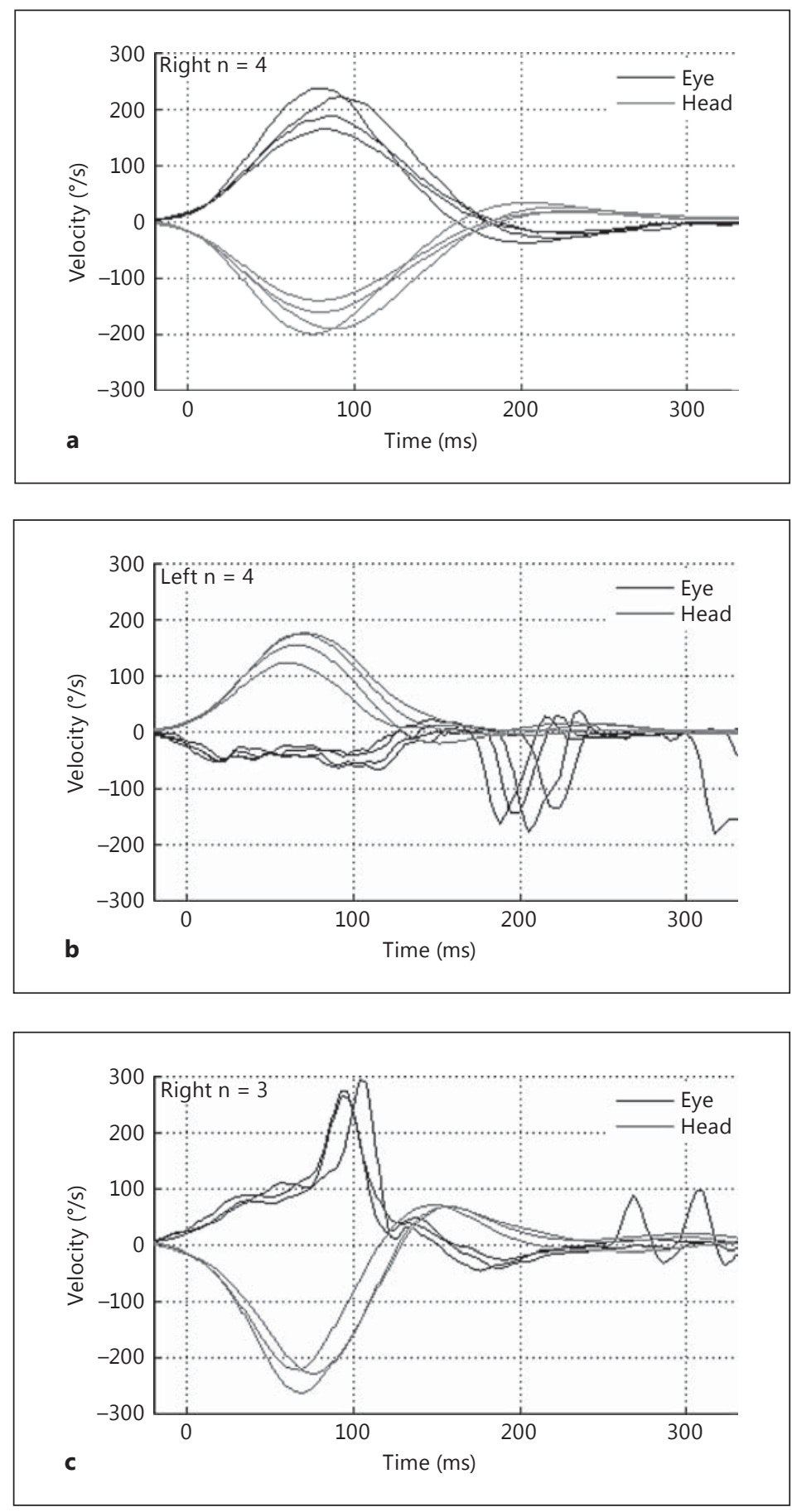

Fig. 1. Raw VHIT recordings of different subjects, recorded with the EyeSeeCam system (EyeSeeCam VOG; EyeSeeCam, Munich, Germany). Head velocity traces are shown in gray, eye velocity traces in black. a VHIT recordings of head impulses to the right in a healthy subject. The eye movements compensate for the passive head movements. b VHIT recordings of head impulses to the left in a patient with a peripheral vestibular deficit, resulting in overt saccades (peaks in eye velocity after head movements). The eye movements do not compensate for the passive head movements. c VHIT recordings of head impulses to the right in a patient with a peripheral vestibular deficit, mainly resulting in covert saccades (peaks in eye velocity during head movements). 


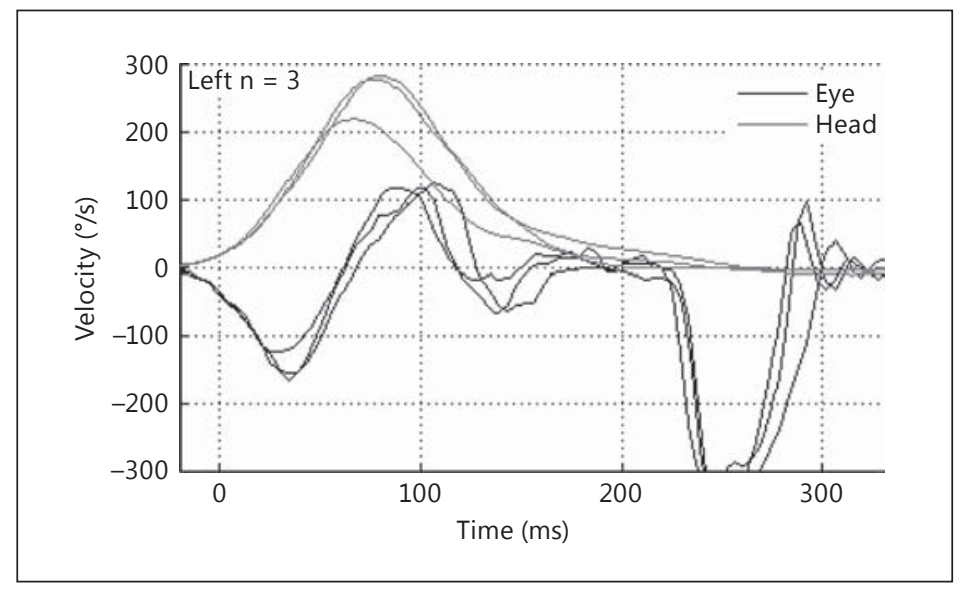

Fig. 2. Example of an eye movement pattern that interferes with gain calculation. Raw VHIT recordings of head impulses to the left in a patient with BVH are presented. Head velocity traces are shown in gray, eye velocity traces in black. Normally, gain is calculated by peak eye velocity divided by peak head velocity. In this case, gain calculation is challenged, since at the moment the peak head velocities are reached, the eyes are actually moving along with the head in the same direction. The passive head movements are not compensated by the eye movements. Although this is clearly an abnormal HIT, there is not yet any consensus about how to determine (or whether it is even possible to determine) the real peak eye velocity which is necessary for gain calculation.

treadmill [100]. A decline of more than 2 lines on the optotype chart is considered abnormal [101], although a loss of 2 lines (0.2 logMAR) is not unusual for healthy subjects. In order to trade sensitivity for specificity, 4 lines may be required [12]. Moreover, DVA may show falsenegative results due to mechanisms that at least partially compensate for the retinal instability during head movements $[84,100]$. However, in subjects with unilateral and bilateral vestibular loss, computerized DVA testing reached a sensitivity of $94.5 \%$ and a specificity of $95.2 \%$ [102]. In another group of BVH patients, DVA was impaired in $96 \%$ of the cases [7]. To conclude, DVA can help establishing the diagnosis of BVH, but a normal DVA does not definitely rule out $\mathrm{BVH}$, and an impaired DVA does not imply vestibular hypofunction per se. It is still not understood by which specific vestibular deficits (which semicircular canals, which otolith organs and which frequencies) DVA decreases.

\section{Caloric Test}

The caloric test, first described by Barany, is believed to evaluate the low-frequency part $(0.003 \mathrm{~Hz})$ of the horizontal semicircular canal function, which is much lower than the frequency spectrum of natural head movements. This, together with the fact that the caloric stimulus is monaural, implies that the test is considered a nonphysiological vestibular test [7, 103-105]. On the other hand, the caloric test is the only widely used clinical test that exclusively stimulates only one side, in contrast to HIT and all other head rotation tests. Based on extensive research in the previous century, the caloric response is believed to be induced by convection [106], aspecific thermic stimulation of hair cells [107] and endolymph expansion [108].

Many challenges are met when using the caloric test for diagnosing BVH. Firstly, it should be performed in a standardized way, since, in order to get reproducible results, all parameters have to be optimized. Therefore, if possible, one should stop medication that influences the vestibular response (e.g. vestibulosuppressants, some antidepressants). Furthermore, the 
room must be completely dark, preventing the patient from being able to visually suppress the elicited vestibulo-ocular reflex, and calibration must be performed prior to each irrigation. A 5-min stimulus interval should be kept between successive irrigations to reduce the residual effects of the previous irrigation. At each irrigation of preferably $30 \mathrm{~s}$, the stimulus must have the same characteristics: the same total volume of at least $250 \mathrm{ml}$ water and the same temperatures for cold and warm irrigations $\left(30\right.$ and $44^{\circ} \mathrm{C}$, respectively) $[54,109]$. A 1-degree variation in temperature from the intended 30 or $44^{\circ} \mathrm{C}$ can already result in a $14 \%$ difference in stimulation magnitude $[110,111]$. The required thermic stimulus is best achieved by the use of water and not by air [109, 112-114]. Statistically higher slowcomponent values of the vestibulo-ocular reflex are obtained for water than for air, and evidence shows that air has a poorer test-retest reliability and greater intersubject variability $[115,116]$. Based on our extensive clinical experience in comparing air calorics to water calorics in many hundreds of patients, we advise using water calorics. However, responses to water calorics also show considerable test-retest variation and variability between healthy subjects [109]. In the past, responses were quantified by slow-phase velocity (in the culmination phase) of the caloric nystagmus, the maximum nystagmus frequency and the total number of nystagmus beats. The maximum slow-phase velocity at the time of maximum response (culmination phase) occurs generally about 50-60 s after the start of irrigation and is the preferred parameter to be determined. Ice water calorics is not preferred, since it can induce a pseudocaloric nystagmus by activating a latent spontaneous nystagmus [7, 117, 118], and the absence of an ice water response does not prove a complete vestibular areflexia, as was thought in the past. After all, it does not exclude normal vestibular responses to the rotatory chair tests or VHIT at all. Besides delivering the right stimulus, all tests should be performed by a trained, attentive and dedicated technician who is able to interpret results to a certain extent. The patient's state of alertness is very important, since cortical activity influences the vestibulo-ocular reflex: the reflex is inhibited by drowsiness. The technician should therefore keep the patient aroused e.g. by asking him/her to perform mental tasks or to focus on the vestibular sensation of rotation. If during irrigation the patient has not been attentive enough, it has to be repeated $[54,119]$. If not repeated, the measured vestibulo-ocular reflex may be lower than in case of optimal alertness, which could lead to a false-positive diagnosis of vestibular hypofunction.

The second challenge is to have the right frame of reference regarding caloric test outcomes. Therefore, a vestibular laboratory must obtain its own up-to-date normative data, since in the literature it has been shown that, due to local factors, caloric test outcomes may vary widely between laboratories $[54,109]$. The average maximum slow-component velocity varies between laboratories from 14.9 to $29.7^{\circ} / \mathrm{s}$ for cold irrigations and from 12.1 to $30.9^{\circ} / \mathrm{s}$ for warm irrigations [54,120-122]. These normative data will probably reveal a high variability among values. For example, in one vestibular laboratory, the $95 \%$ prediction interval of the average maximum slow-component velocity may vary from 3.4 to $32.9^{\circ} / \mathrm{s}$ for cold irrigations and from 6.9 to $55.0^{\circ} \mathrm{s}$ for warm irrigations. There is as yet no unanimity among investigators about correcting values for age [123-126]. Also, the asymmetry between labyrinths may be up to $19 \%$, and still be within the normal range [54]. This variability may partly be due to uncontrollable factors such as differences in anatomy of the temporal bone (differences in temperature conduction), blood flow and middle ear fluids - all the more reason to have controllable factors such as stimulus parameters and technical skills optimized and to absolutely avoid any visual suppression [54].

The third challenge is, again, to correctly interpret the values. For BVH, it is first of all important to not only look at the asymmetry. Some laboratories only report the asymmetry between ears, without reporting the total response. This could result in false-negative errors [12]. However, while it is necessary to take the total response into account, there is still no 
van de Berg et al.: Bilateral Vestibular Hypofunction: Challenges in Establishing the Diagnosis in Adults

consensus on the range of responses required for the diagnosis of $\mathrm{BVH}[7,10,118,127]$. A criterion often suggested for diagnosing BVH is to have a sum of 4 irrigations that is less than $20^{\circ} / \mathrm{s}[7,12,18,95]$. While this is highly specific, it could still lead to false-positive results (partly due to the anatomical variations mentioned above) and also, very importantly, to false-negative results. The sum of 4 irrigations in one laboratory can already vary from 27 to $169^{\circ} / \mathrm{s}$ [54]. This implies that using a sum of less than $20^{\circ} / \mathrm{s}$ will possibly lead to 'milder' types of BVH being missed. One of the main problems with the caloric test is the fact that a physician will hardly ever know what would have been the initial response values of a patient for the caloric test. A patient often visits a physician for the first time, when vestibular complaints are already present. It is therefore not known when the measured response is low, whether it is a reflection of already induced vestibular damage or just the physiological initial response. This remains a challenge. Depending on the criteria for BVH, some authors show that the caloric test only has a sensitivity of $64.6 \%$. This could be the result of highly specific criteria, anatomical differences or measuring a nonphysiological stimulus, but it could also be due to the fact that only the lateral semicircular canal is tested by the caloric test [81]. Other parts of the vestibular system are not tested, such as the remaining semicircular canals and the otolith organs.

To summarize, using the caloric test for diagnosing BVH is challenging, due to the high standards necessary for testing and difficult interpretation as a result of inter- and intrasubject variation for which the present diagnostic criteria for BVH are not always sufficient. When the high testing standards are not adhered to, and the inter- and intrasubject variability is not taken into account, this will lead to unnecessary false-positive and false-negative diagnoses of BVH.

\section{Rotatory Chair Tests}

Rotatory chair tests could demonstrate residual vestibular function in patients with severe BVH, when (almost) no vestibular response is measured with the caloric test [128130]. It can also provide additional data about central processing of vestibular input from both labyrinths [54]. Two frequently used algorithms are the sinusoidal harmonic acceleration test (SHAT) and the velocity step test (VST) [131]. The SHAT is often promoted as a real multifrequency rotation test. However, compared to the optimum frequency sensitivity of the semicircular canals (ranging from about 0.1 to $10 \mathrm{~Hz}$ ), the SHAT uses only low-frequency stimuli ranging from 0.005 to a maximum of $0.64 \mathrm{~Hz}$. Another complicating factor is that the total SHAT takes considerable time. Therefore, the frequency response might be affected by changes in alertness of the patient during the test.

The VST involves more high-frequency components compared to the SHAT (step function) and comes closer to HIT. The first challenge when performing rotatory chair testing is to conduct it in a standardized way. One should always stop medication that influences the vestibular response, if possible. Furthermore, the room should be completely dark to avoid fixation suppression and optokinetic stimuli. The patient must be alert, since alertness during rotation increases the gain of the measured vestibulo-ocular reflex [54]. It is necessary to have a well-trained, dedicated and attentive technician who is able to interpret results to a certain extent. In this way the patient can be kept alert and measurements can be directly repeated when suboptimal responses are encountered. If the patient is not alert and the technician does not recognize this, the measured vestibulo-ocular reflex may be lower than in reality. This could result in a false-positive diagnosis of vestibular hypofunction. Many vestibular laboratories prefer to have the eyes of the patient open during testing, since closing the eyes decreases gain of the vestibulo-ocular reflex [132]. For the VST, it is preferred to use the first rotation for familiarization with the test to get responses as accurate as possible [131]. 
The second challenge is to have the right frame of reference for the rotatory tests. Regarding gain of the vestibulo-ocular reflex, its values differ very much between vestibular laboratories for the SHAT as well as for the VST. It is therefore necessary for each vestibular laboratory to have its own normative data $[131,133,134]$. Furthermore, in the SHAT and the VST, gain is considered to be the most variable parameter between and within subjects, probably as a consequence of factors such as fatigue, alertness, stress and habituation [119, $131,135,136]$. Gain is also reduced by the test itself; rotating in the dark is an artificial condition that reduces gain $[137,138]$. Moreover, gain is frequency dependent: it increases to a certain extent with an increasing modulation frequency $[119,139]$. Taking all these facts into account, normative data for a vestibular laboratory can vary widely: for the SHAT, a mean gain of $58.77 \%$ with a standard deviation of $13.98 \%\left(0.1 \mathrm{~Hz}, 50^{\circ} / \mathrm{s}\right.$ peak velocity $)$, and for the VST, a mean gain of $67.66 \%$ with a standard deviation of $18.14 \%\left(200^{\circ} / \mathrm{s}^{2} \mathrm{de}\right.$ celeration after a continuous velocity of $100 \%$ s rotating to the right). However, it has been indicated that SHAT and VST gain parameters can be highly reliable, despite the fact that they are influenced by many other factors [131]. Regarding other parameters, directional preponderance can vary widely within one vestibular laboratory, up to a 95\% prediction interval of $26 \%\left(0.05 \mathrm{~Hz}, 50^{\circ} / \mathrm{s}\right.$ peak velocity) [54]. Parameters that are believed to be more consistent and reproducible are 'phase' in the SHAT and 'time constant' in the VST. They are not influenced by the arousal state of the patient [131, 135, 140-142]. The literature about the influence of sex differences on response parameters is not really consistent [135].

All these facts show that interpreting the results correctly is the last challenge when using the rotatory chair for diagnosing BVH. Some authors suggest that rotatory chair tests should be the gold standard $[12,143]$. If any abnormalities are found in BVH patients, the strongest effects are often found at low frequencies, with a decrease in gain and an increase in phase [12]. However, depending on the criteria, only $53 \%$ of BVH patients show abnormal responses on the rotatory chair. This emphasizes the need for establishing a standardized protocol for the diagnosis of BVH patients. Until now, the modulation frequencies necessary to be tested and the cutoff criteria have not yet been established [7, 144]. As with caloric testing, a borderline low response, for instance, may be the result of damage due to a vestibular disorder or be just a physiological phenomenon. Without knowing the initial values of a patient, the etiology of the low response will remain questionable.

To summarize, use of the rotatory chair is challenging. In order to get reproducible and consistent results, a high standard for testing is necessary. Due to inter- and intrasubject variation in some parameters, interpretation of the results remains difficult and the diagnostic criteria for BVH are not yet established for this test. It seems that the rotatory chair can be used complementarily with other vestibular tests [145], but not as the only test in the diagnostic process of BVH.

\section{Vestibular Evoked Myogenic Potentials}

VEMPs are electromyogenic potentials elicited by high-intensity, transient acoustic stimuli and recorded from surface electrodes over tonically contracted muscles. Different types of VEMP are recorded from neck muscles [cervical VEMPs (cVEMPs)] or ocular muscles [ocular VEMPs (oVEMPs); for an overview, see Curthoys [146]], and both have been incorporated as part of the vestibular testing battery in many clinics worldwide. A major difference is that the oVEMP is a contralateral response, whereas the cVEMP is an ipsilateral response. This is shown in a study in which the oVEMP was absent on the contralateral side in patients with unilateral vestibular function, but present on the ipsilateral side [147]. Furthermore, the cVEMP is an inhibitory response and the oVEMP is excitatory, as shown in a single-motor unit recording study [148]. The more uncertain parts of the tests are related to the end organ 
responsible for the response. It has been proposed that the oVEMP is mainly mediated by utricular stimulation, while the cVEMP is a saccular response [149].

In order to use VEMPs as a diagnostic tool, it is imperative to identify, understand, and when possible, control the pitfalls in VEMP testing. Firstly, it is important to realize that there is no standardized testing method, not for the cVEMP and even less so for the oVEMP [150, 151]. Many variables have been described to influence the outcome (patient position, electrode placement, frequency and intensity of the stimulus, etc.). Although general guidelines have been published [152], improvements are needed before VEMPs can be considered a reliable test. Since no standardized method is used, it is difficult to compare outcomes between studies. Therefore, it necessary for each laboratory to gather its own normative database from which pathological outcomes can be evaluated. This database should contain VEMP responses of healthy subjects of varying age groups, since both cVEMPs and oVEMPs show reduced outcomes with increasing age $[153,154]$.

Secondly, different VEMP outcome metrics can be used to assess vestibular function. Recent studies have described the use of the interaural asymmetry ratio to compare the left with the right ear in order to aid in identifying the affected ear in Menière's disease [155]. In strictly unilateral diseases this could be a helpful outcome; however, when there is a suspicion or chance that both ears are affected, this ratio could underestimate the disease [156]. Therefore, in BVH this outcome measurement has little value. Peak-to-peak amplitude is another method of assessing the VEMP waveform, in which the distance between positive and negative peaks is measured. For cVEMPs as well as oVEMPs, the peak-to-peak amplitude changes when the vestibular apparatus is affected, and this response varies by the stimulus frequency [157]. Therefore, it is preferable to measure VEMPs with multiple stimulus frequencies $[158,159]$. In most of the current literature, only a single measurement, made at one frequency, was used to assess VEMP response (mostly at $500 \mathrm{~Hz}$ ), which substantially limits the sensitivity of the test. Peak-to-peak amplitude also co-varies with muscle contraction intensity, which can be a significant confounding variable. Recent studies have shown that normalization of the VEMP response during signal processing to correct for the muscle activity significantly reduces the variability in cVEMPs in healthy subjects [160]. Also, VEMP thresholds at multiple frequencies yield, at least in Menière's disease patients, a more sensitive measure with less intersubject variability (in normals), further increasing the clinical utility of the cVEMP [van Tilburg et al., submitted paper]. Threshold measurements in oVEMPs have also been shown to differ between healthy and pathological subjects [161]. Furthermore, using only a present/absent criterion, the degree of damage to the otoliths is not measurable. A recent study showed that there was a significant decrease in cVEMP threshold in Menière's disease patients when these patients were tested 2 times with at least 3 months between tests, suggesting a progressive decrease in otolith function [van Tilburg et al., submitted paper]. The unaffected ear showed no significant difference in threshold.

Thirdly, it is important to correctly interpret the results. Some studies use VEMPs in the evaluation of BVH; however, the application of VEMPs is often not optimal, making it difficult to interpret the results. Two papers described patients with absent cVEMPs and normal caloric responses, demonstrating a new subtype of idiopathic bilateral vestibulopathy called 'dissociated bilateral vestibulopathy' $[11,80]$. However, some patients were older than 70 years, in which case age could also be a very likely (physiological) explanation for the absent responses. Other patients had vertigo attacks, and even though they did not have hearing loss, this could be a first sign of Menière's disease, since some of them were still young (below 45 years). Although it is most likely that BVH can affect different parts of the vestibular system separately $[18,19]$, an absent response of VEMPs does not indicate a vestibular deficit per se.

In conclusion, VEMP testing is an emerging and valuable addition to the vestibular function testing 'toolbox', since it permits an assessment of each otolith organ in a way not 
previously available. The details of the underlying physiology and the precise methods of performing, analyzing and interpreting VEMP responses are still evolving and not yet standardized. More research is needed to determine how VEMPs are most accurately performed and interpreted.

\section{Other Diagnostic Tests}

The value of posturography in the diagnosis of BVH is limited, since it lacks specificity. It does not discriminate very well between vestibular disorders and other causes of imbalance such as cerebellar ataxia [12]. The accuracy of subjective visual vertical testing for BVH has still to be refined [162]. Many other tests can also be used in the diagnostic process if necessary: audiometry, measuring blood pressure, measuring orthostatic hypotension, blood tests (including autoantibodies, complement factors, folate, vitamin $\mathrm{B}_{12}$, renal function, thyroid function, glucose, genetics, etc.), imaging (e.g. magnetic resonance imaging, computed tomography), lumbar puncture, sensory nerve action potentials, speech assessment, etc. [18-20, 23, 40, 89]. However, these tests are mainly used for determination of coexisting problems or the etiology of BVH (table 1), not for an evaluation of vestibular function. Since they do not specifically contribute to establishing the presence of BVH, they are not within the scope of this review.

\section{Challenge Four: Establishing the Diagnosis of BVH}

To establish a correct diagnosis in vestibular patients is difficult: a clear diagnosis is not possible in up to $40 \%$ of vertigo patient subgroups [4]. As may be concluded from the challenges mentioned above, establishing the diagnosis of BVH is not an exception to this: it can be complicated. This results from its often difficult clinical presentation (e.g. vertigo does not always occur), the lack of uniform criteria for BVH, the heterogeneity of BVH, different settings in which patients are seen (otorhinolaryngology, neurology, ophthalmology, etc.), the tradeoff between sensitivity and specificity for each test which determines the cutoff criteria, the (inherent) shortcomings of the tests and the fact that patients' subjective sensations do not always match up with the objective laboratory measures $[3,7,18,54]$. Regarding criteria for BVH, different ones can be used which could probably complement each other. Three examples extracted from the literature are shown in table 2 [7, 12, 80, 163].

As shown, there are still challenges regarding all the options. For example, the criteria in table 2a do not take tests of otolith function into account. This could lead to an underestimation of BVH when considering the option of dissociated bilateral vestibulopathy. Furthermore, the cutoff criterion for reduced caloric responses probably mainly yields a high specificity. Sensitivity may be put at a disadvantage in less severe cases of BVH or in individuals with high initial caloric responses (before they developed BVH). Also, the criterion of a reduced gain for rotatory chair testing is not defined. The (partial) definition on the basis of the parts affected displayed in table $2 \mathrm{~b}$ only uses the present/absent criterion for VEMPs, which could lead to an underestimation of BVH. On the other hand, it does not yet consider a physiological or age-related absence of VEMPs, which could lead to an overestimation of BVH. Table 2c shows a (partial) definition of BVH on the basis of severity. However, it is a challenge to define vestibular loss; for instance, caloric and rotatory chair tests have a broad range of normative data. It is questionable to determine the extent of vestibular loss if the initial values are not known. Also, the definition does not specify whether it comprises only vestibular loss or also loss in functional parameters. After all, as stated earlier, patients' subjective sensations do not always match the results of the laboratory tests [7]. One of the factors contributing to this issue could be the basic health condition of patients. For example, in obstructive sleep apnea, this is given as one of the explanations why some patients are able to withstand a certain amount of sleep disruption better than others [164]. Therefore, the severity of obstructive sleep apnea may be determined by objective laboratory findings, combined with 
Table 2. Examples of BVH criteria extracted from the current literature van de Berg et al.: Bilateral Vestibular Hypofunction: Challenges in Establishing the Diagnosis in Adults

a BVH defined as a combination of history and laboratory findings [7]

1. Symptoms only during locomotion

Unsteadiness and/or

Oscillopsia

2. Bedside evaluation

Positive HIT and/or

Impaired DVA

3. Laboratory tests

Reduced caloric responses (sum SPV $<20^{\circ} /$ s) and/or

Reduced gain on rotatory chair

4. Other causes excluded

Evaluation

Definite diagnosis: met all 4 diagnostic criteria

Probable diagnosis: met criterion 2 or 3 in addition to criteria 1 and 4

b BVH (partially) defined on the basis of the affected parts of the vestibular organs $[80,163]$

c BVH (partially) defined on the basis of severity [12]

Severe: $75-100 \%$ vestibular loss

Moderate: $50-75 \%$ vestibular loss

Mild: $0-50 \%$ vestibular loss

SPV = Slow-phase velocity

daytime sleepiness as measured by a short questionnaire [164]. For some vestibular patient groups, such an influence of their basic health condition has already been known for physical as well as mental domains: imbalance is often greater in patients with CANVAS, due to the comorbidity of polyneuropathy and ataxia [89], and patients with an anxious, introverted temperament could be more prone to develop chronic subjective dizziness [165]. However, also less well-known factors could belong to the basic health condition, such as the ability to effectively use mechanisms that at least partially compensate for the consequences of vestibular hypofunction [100]. The severity of BVH can therefore most likely be determined not only by objective laboratory findings but also by using a combination of objective laboratory findings together with a specification of the handicap related to the dizziness. For hearing-impaired patients, functional hearing ability is partially assessed by speech audiometry. Since there is as yet no vestibular 'speech audiogram', functional impairment due to $\mathrm{BVH}$ is at this moment probably best measured by using questionnaires.

Overall, establishing the diagnosis of BVH in a patient with a severely affected vestibular system could very well be possible, since patient history and vestibular tests, when correctly applied and interpreted, will all be indicative of BVH. However, in many cases, the vestibular system is less severely affected, or strong compensatory mechanisms or psychological comorbidity play a role. In these patients, establishing the diagnosis of BVH is a great challenge at 
van de Berg et al.: Bilateral Vestibular Hypofunction: Challenges in Establishing the Diagnosis in Adults

this moment. It still remains up to the physician, who has to combine the clinical picture and outcomes of (not all congruent) objective laboratory tests, to decide whether a patient suffers from BVH or not.

\section{Future in Diagnosing BVH}

There is an urgent need for diagnostic standardization regarding the implementation and interpretation of vestibular tests. The resulting decisions should be used for the development of uniform diagnostic criteria for BVH. Regarding vestibular tests, besides standardizing their implementation, an evaluation of cutoff points for BVH is necessary. At this moment, cutoff points are mainly in favor of a high specificity, putting sensitivity at a disadvantage, especially in caloric and rotatory chair tests. For VHIT, defining the interpretation of traces is necessary; quantification is not always possible, and physicians cannot yet solely rely on software. Concerning DVA, determining various aspects could be helpful in establishing the diagnosis of BVH. It has not been extensively investigated in milder clinical presentations of BVH, lacking evidence of its value in these patients. Also, the best way to perform DVA testing is not uniform (e.g. passively shaking the head, walking on a treadmill). For VEMPs, criteria should be defined as to how to perform, analyze and interpret them. Once this is established, VEMPs must be included in the criteria for $\mathrm{BVH}$, especially taking the possibility of otolith involvement into account.

Regarding criteria, we would propose BVH to be established on the basis of a combination of patient history, physical examination, vestibular tests (including VEMPs) and perceived handicap as measured by questionnaires (e.g. the Dizziness Handicap Inventory). Once established, BVH could be classified according to severity, taking not only objective measures but also functional impairment into account. A classification according to severity could be important, since much progress has been made in developing a vestibular implant [144, 166-168] and such a classification could facilitate patient selection. If necessary, a subdivision into probability groups (e.g. definite BVH, probable BVH, etc.) can be made to facilitate decision making in cases with less congruent test results. The role of measurements of vestibular perceptual thresholds is not yet certain, but if they will develop into one of the standard routine vestibular tests, they might become the 'speech audiogram' for vestibular disorders. In close cooperation with other societies and institutions, the International Standardization Committee of the Bárány Society has defined new international standards for several vestibular syndromes (e.g. benign paroxysmal positional vertigo, Menière's disease, vestibular migraine). It is, among others, currently working on a definition of BVH, including diagnostic criteria.

\section{Conclusions}

Many challenges are met when establishing the diagnosis of BVH. These reflect its often difficult clinical presentation (e.g. vertigo does not always occur) and the lack of diagnostic standards regarding the implementation and interpretation of vestibular tests. Therefore, there is an urgent need for standardization. The resulting decisions should be used for the development of uniform diagnostic criteria for BVH, which are, at present, not yet available.

\section{Disclosure Statement}

The authors declare that they have no conflicts of interest. 
van de Berg et al.: Bilateral Vestibular Hypofunction: Challenges in Establishing the Diagnosis in Adults

\section{References}

1 Gopinath B, McMahon CM, Rochtchina E, Mitchell P: Dizziness and vertigo in an older population: the Blue Mountains prospective cross-sectional study. Clin Otolaryngol 2009;34:552-556.

-2 Geser R, Straumann D: Referral and final diagnoses of patients assessed in an academic vertigo center. Front Neurol 2012;3:169.

3 Grill E, Strupp M, Müller M, Jahn K: Health services utilization of patients with vertigo in primary care: a retrospective cohort study. J Neurol 2014;261:1492-1498.

$\checkmark 4$ Roberts DS, Lin HW, Bhattacharyya N: Health care practice patterns for balance disorders in the elderly. Laryngoscope 2013;123:2539-2543.

5 Vibert D, Liard P, Häusler R: Bilateral idiopathic loss of peripheral vestibular function with normal hearing. Acta Otolaryngol 1995;115:611-615.

-6 Ward BK, Agrawal Y, Hoffman HJ, Carey JP, Della Santina CC: Prevalence and impact of bilateral vestibular hypofunction: results from the 2008 US National Health Interview Survey. JAMA Otolaryngol Head Neck Surg 2013;139:803-810.

7 Kim S, Oh YM, Koo JW, Kim JS: Bilateral vestibulopathy: clinical characteristics and diagnostic criteria. Otol Neurotol 2011;32:812-817.

-8 Guinand N, Boselie F, Guyot JP, Kingma H: Quality of life of patients with bilateral vestibulopathy. Ann Otol Rhinol Laryngol 2012;121:471-477.

-9 Porciuncula F, Johnson CC, Glickman LB: The effect of vestibular rehabilitation on adults with bilateral vestibular hypofunction: a systematic review. J Vestib Res 2012;22:283-298.

10 McGath JH, Barber HO, Stoyanoff S: Bilateral vestibular loss and oscillopsia. J Otolaryngol 1989;18:218-221.

11 Fujimoto C, Murofushi T, Sugasawa K, Chihara Y, Ushio M, Yamasoba T, et al: Bilateral vestibulopathy with dissociated deficits in the superior and inferior vestibular systems. Ann Otol Rhinol Laryngol 2012;121:383388.

12 Hain TC, Cherchi M, Yacovino DA: Bilateral vestibular loss. Semin Neurol 2013;33:195-203.

13 Kingma H, Stokroos R, Manni JJ: Aandoeningen van het evenwichtssysteem; in Huizing EH, Snow GB (eds): Leerboek keel-, neus- en oorheelkunde. Houten, Bohn Stafleu van Loghum, 2005, p 151.

14 van de Berg R, Guinand N, Stokroos RJ, Guyot JP, Kingma H: The vestibular implant: quo vadis? Front Neurol 2011;2:47.

-15 Della Santina CC, Migliaccio AA, Patel AH: A multichannel semicircular canal neural prosthesis using electrical stimulation to restore 3-D vestibular sensation. IEEE Trans Biomed Eng 2007;54(6 pt 1):1016-1030.

$\checkmark 16$ Lacour M, Dutheil S, Tighilet B, Lopez C, Borel L: Tell me your vestibular deficit, and I'll tell you how you'll compensate. Ann NY Acad Sci 2009;1164:268-278.

17 Dandy WE: The surgical treatment of Meniere's disease. Surg Gynecol Obstet 1941;72:421-425.

-18 Zingler VC, Weintz E, Jahn K, Bötzel K, Wagner J, Huppert D, et al: Saccular function less affected than canal function in bilateral vestibulopathy. J Neurol 2008;255:1332-1336.

19 Jen JC: Bilateral vestibulopathy: clinical, diagnostic, and genetic considerations. Semin Neurol 2009;29:528533.

20 Zingler VC, Weintz E, Jahn K, Huppert D, Cnyrim C, Brandt T, et al: Causative factors, epidemiology, and followup of bilateral vestibulopathy. Ann NY Acad Sci 2009;1164:505-508.

-21 Zingler VC, Weintz E, Jahn K, Mike A, Huppert D, Rettinger N, et al: Follow-up of vestibular function in bilateral vestibulopathy. J Neurol Neurosurg Psychiatry 2008;79:284-288.

22 Rinne T, Bronstein AM, Rudge P, Gresty MA, Luxon LM: Bilateral loss of vestibular function: clinical findings in 53 patients. J Neurol 1998;245:314-321.

-23 Szmulewicz DJ, Waterston JA, MacDougall HG, Mossman S, Chancellor AM, McLean CA, et al: Cerebellar ataxia, neuropathy, vestibular areflexia syndrome (CANVAS): a review of the clinical features and video-oculographic diagnosis. Ann NY Acad Sci 2011;1233:139-147.

-24 Weekamp HH, Huygen PL, Merx JL, Kremer HP, Cremers CW, Longridge NS: Longitudinal analysis of hearing loss in a case of hemosiderosis of the central nervous system. Otol Neurotol 2003;24:738-742.

25 Kale SU, Donaldson I, West RJ, Shehu A: Superficial siderosis of the meninges and its otolaryngologic connection: a series of five patients. Otol Neurotol 2003;24:90-95.

26 Black FO, Pesznecker S, Stallings V: Permanent gentamicin vestibulotoxicity. Otol Neurotol 2004;25:559-569.

-27 Lemaire FX, Feenstra L, Huygen PL, Fransen E, Devriendt K, Van Camp G, et al: Progressive late-onset sensorineural hearing loss and vestibular impairment with vertigo (DFNA9/COCH): longitudinal analyses in a Belgian family. Otol Neurotol 2003;24:743-748.

-28 Jen JC, Wang H, Lee H, Sabatti C, Trent R, Hannigan I, et al: Suggestive linkage to chromosome 6q in families with bilateral vestibulopathy. Neurology 2004;63:2376-2379.

-29 Gazquez I, Lopez-Escamez JA: Genetics of recurrent vertigo and vestibular disorders. Curr Genomics 2011;12: 443-450.

30 Watanabe M, Miyasaka H, Iwata N, Maeda S, Kishida S, Hayashi H: A case of superficial siderosis of the central nervous system with bilateral vestibular dysfunction (in Japanese). No To Shinkei 1997;49:931-935.

-31 Guyot JP, Liard P, Thielen K, Kos I: Isolated vestibular areflexia after blunt head trauma. Ann Otol Rhinol Laryngol 2001;110:562-564. 
van de Berg et al.: Bilateral Vestibular Hypofunction: Challenges in Establishing the Diagnosis in Adults

-32 Murofushi T, Ouvrier RA, Parker GD, Graham RI, da Silva M, Halmagyi GM: Vestibular abnormalities in charge association. Ann Otol Rhinol Laryngol 1997;106:129-134.

-33 Nuti D, Passero S, Di Girolamo S: Bilateral vestibular loss in vertebrobasilar dolichoectasia. J Vestib Res 1996; 6:85-91.

-34 Tamagawa Y, Ishikawa K, Ishikawa K, Ishida T, Kitamura K, Makino S, et al: Phenotype of DFNA11: a nonsyndromic hearing loss caused by a myosin VIIA mutation. Laryngoscope 2002;112:292-297.

-35 Bischoff AM, Pennings RJ, Huygen PL, Luijendijk MW, van Wijk E, Cruysberg JR, et al: Cochleovestibular and ocular features in a Dutch DFNA11 family. Otol Neurotol 2006;27:323-331.

$\$ 36$ Wenzel A, Ward BK, Schubert MC, Kheradmand A, Zee DS, Mantokoudis G, et al: Patients with vestibular loss, Tullio phenomenon, and pressure-induced nystagmus: vestibular atelectasis? Otol Neurotol 2014;35:866872.

37 Greco A, De Virgilio A, Gallo A, Fusconi M, Ruoppolo G, Turchetta R, et al: Idiopathic bilateral vestibulopathy: an autoimmune disease? Autoimmun Rev 2014;13:1042-1047.

-38 Hirvonen TP, Aalto H: Recovery of bilateral vestibular loss in Cogan's syndrome - a case report. Otol Neurotol 2013;34:1736-1738.

-39 Hertel S, Schwaninger M, Helmchen C: Combined toxicity of penicillin and aspirin therapy may elicit bilateral vestibulopathy. Clin Neurol Neurosurg 2013;115:1114-1116.

40 Requena T, Espinosa-Sanchez JM, Lopez-Escamez JA: Genetics of dizziness: cerebellar and vestibular disorders. Curr Opin Neurol 2014;27:98-104.

41 Ahmed RM, Hannigan IP, MacDougall HG, Chan RC, Halmagyi GM: Gentamicin ototoxicity: a 23-year selected case series of 103 patients. Med J Aust 2012;196:701-704.

-42 Fischer CS, Bayer 0, Strupp M: Transient bilateral vestibular dysfunction caused by intoxication with low doses of styrene. Eur Arch Otorhinolaryngol 2014;271:619-623.

-43 Baxter M, Agrawal Y: Vestibular dysfunction in Turner syndrome: a case report. Otol Neurotol 2014;35:294296.

44 Viana LM, Salviz M, Rauch SD, Nadol JB: Otopathology in idiopathic Dandy's syndrome. Otol Neurotol 2013; 34:1099-1103.

45 Grunfeld EA, Morland AB, Bronstein AM, Gresty MA: Adaptation to oscillopsia: a psychophysical and questionnaire investigation. Brain 2000;123(pt 2):277-290.

-46 Sun DQ, Ward BK, Semenov YR, Carey JP, Della Santina CC: Bilateral vestibular deficiency: quality of life and economic implications. JAMA Otolaryngol Head Neck Surg 2014, Epub ahead of print.

47 Rine RM, Wiener-Vacher S: Evaluation and treatment of vestibular dysfunction in children. NeuroRehabilitation 2013;32:507-518.

-48 Wiener-Vacher SR, Obeid R, Abou-Elew M: Vestibular impairment after bacterial meningitis delays infant posturomotor development. J Pediatr 2012;161:246-251.e1.

49 Guerraz M, Yardley L, Bertholon P, Pollak L, Rudge P, Gresty MA, et al: Visual vertigo: symptom assessment, spatial orientation and postural control. Brain 2001;124(pt 8):1646-1656.

50 Newman-Toker DE, Cannon LM, Stofferahn ME, Rothman RE, Hsieh YH, Zee DS: Imprecision in patient reports of dizziness symptom quality: a cross-sectional study conducted in an acute care setting. Mayo Clin Proc 2007; 82:1329-1340.

51 Carey JP, Della Santina CC: Principles of applied vestibular physiology; in Cummings CW, et al (eds): Cummings Otolaryngology: Head and Neck Surgery, ed 4. Philadelphia, Elsevier Mosby, 2005, p 3116.

52 McCall AA, Yates BJ: Compensation following bilateral vestibular damage. Front Neurol 2011;2:88.

53 Kim HJ, Lee JO, Koo JW, Kim JS, Ban J: Gentamicin-induced bilateral vestibulopathy in rabbits: vestibular dysfunction and histopathology. Laryngoscope 2013;123:E51-E58.

54 Van Der Stappen A, Wuyts FL, Van De Heyning PH: Computerized electronystagmography: normative data revisited. Acta Otolaryngol 2000;120:724-730.

55 Leigh RJ, Zee DS: Diagnosis and Management of Vestibular Disorders. The Neurology of Eye Movements, ed 4. New York, Oxford University Press, 2006, p 578.

56 Guinand N, Pijnenburg M, Janssen M, Kingma H: Visual acuity while walking and oscillopsia severity in healthy subjects and patients with unilateral and bilateral vestibular function loss. Arch Otolaryngol Head Neck Surg 2012;138:301-306.

57 Demer JL, Honrubia V, Baloh RW: Dynamic visual acuity: a test for oscillopsia and vestibulo-ocular reflex function. Am J Otol 1994;15:340-347.

-58 Telian SA, Shepard NT, Smith-Wheelock M, Hoberg M: Bilateral vestibular paresis: diagnosis and treatment. Otolaryngol Head Neck Surg 1991;104:67-71.

59 Glasauer S, Amorim MA, Vitte E, Berthoz A: Goal-directed linear locomotion in normal and labyrinthinedefective subjects. Exp Brain Res 1994;98:323-335.

60 Guerraz M, Day BL: Expectation and the vestibular control of balance. J Cogn Neurosci 2005;17:463-469.

61 Bisdorff AR, Wolsley CJ, Anastasopoulos D, Bronstein AM, Gresty MA: The perception of body verticality (subjective postural vertical) in peripheral and central vestibular disorders. Brain 1996;119(pt 5):15231534.

62 Cutfield NJ, Scott G, Waldman AD, Sharp DJ, Bronstein AM: Visual and proprioceptive interaction in patients with bilateral vestibular loss. Neuroimage Clin 2014;4:274-282. 
van de Berg et al.: Bilateral Vestibular Hypofunction: Challenges in Establishing the Diagnosis in Adults

63 Göttlich M, Jandl NM, Wojak JF, Sprenger A, der Gablentz J, Münte TF, et al: Altered resting-state functional connectivity in patients with chronic bilateral vestibular failure. Neuroimage Clin 2014;4:488-499.

64 Dieterich M, Bauermann T, Best C, Stoeter P, Schlindwein P: Evidence for cortical visual substitution of chronic bilateral vestibular failure (an fMRI study). Brain 2007;130(pt 8):2108-2116.

-65 Bronstein AM: Visual vertigo syndrome: clinical and posturography findings. J Neurol Neurosurg Psychiatry 1995;59:472-476.

66 Hanes DA, McCollum G: Cognitive-vestibular interactions: a review of patient difficulties and possible mechanisms. J Vestib Res 2006;16:75-91

67 Bessot N, Denise P, Toupet M, Van Nechel C, Chavoix C: Interference between walking and a cognitive task is increased in patients with bilateral vestibular loss. Gait Posture 2012;36:319-321.

68 Lundin-Olsson L, Nyberg L, Gustafson Y: 'Stops walking when talking' as a predictor of falls in elderly people. Lancet 1997;349:617.

-69 Zheng Y, Wilson G, Stiles L, Smith PF: Glutamate receptor subunit and calmodulin kinase II expression, with and without $T$ maze training, in the rat hippocampus following bilateral vestibular deafferentation. PLoS One 2013;8:e54527.

70 Viard A, Doeller CF, Hartley T, Bird CM, Burgess N: Anterior hippocampus and goal-directed spatial decision making. J Neurosci 2011;31:4613-4621.

71 Zheng Y, Balabhadrapatruni S, Baek JH, Chung P, Gliddon C, Zhang M, et al: The effects of bilateral vestibular loss on hippocampal volume, neuronal number, and cell proliferation in rats. Front Neurol 2012;3:20.

72 Brandt T, Schautzer F, Hamilton DA, Brüning R, Markowitsch HJ, Kalla R, et al: Vestibular loss causes hippocampal atrophy and impaired spatial memory in humans. Brain 2005;128(pt 11):2732-2741.

73 Smith PF, Haslett S, Zheng Y: A multivariate statistical and data mining analysis of spatial memory-related behaviour following bilateral vestibular loss in the rat. Behav Brain Res 2013;246:15-23.

74 Fanselow MS, Dong HW: Are the dorsal and ventral hippocampus functionally distinct structures? Neuron 2010;65:7-19.

75 Baijens LW, Verdonschot R, Vanbelle S, Basic S, Kremer B, van de Berg R, et al: Medically unexplained otorhinolaryngological symptoms: towards integrated psychiatric care. Laryngoscope 2015;125:1583-1587.

76 Ketola S, Havia M, Appelberg B, Kentala E: Psychiatric symptoms in vertiginous patients. Nord J Psychiatry 2015;69:287-291.

77 Highstein SM, Holstein GR: The anatomical and physiological framework for vestibular prostheses. Anat Rec (Hoboken) 2012;295:2000-2009.

78 Holstein GR, Friedrich VL Jr, Kang T, Kukielka E, Martinelli GP: Direct projections from the caudal vestibular nuclei to the ventrolateral medulla in the rat. Neuroscience 2011;175:104-117.

79 Balaban CD: Projections from the parabrachial nucleus to the vestibular nuclei: potential substrates for autonomic and limbic influences on vestibular responses. Brain Res 2004;996:126-137.

80 Fujimoto C, Murofushi T, Chihara Y, Suzuki M, Yamasoba T, Iwasaki S: Novel subtype of idiopathic bilateral vestibulopathy: bilateral absence of vestibular evoked myogenic potentials in the presence of normal caloric responses. J Neurol 2009;256:1488-1492.

-81 Priesol AJ, Valko Y, Merfeld DM, Lewis RF: Motion perception in patients with idiopathic bilateral vestibular hypofunction. Otolaryngol Head Neck Surg 2014;150:1040-1042.

82 Weber KP, Aw ST, Todd MJ, McGarvie LA, Curthoys IS, Halmagyi GM: Horizontal head impulse test detects gentamicin vestibulotoxicity. Neurology 2009;72:1417-1424.

-83 Kattah JC, Talkad AV, Wang DZ, Hsieh YH, Newman-Toker DE: HINTS to diagnose stroke in the acute vestibular syndrome: three-step bedside oculomotor examination more sensitive than early MRI diffusion-weighted imaging. Stroke 2009;40:3504-3510.

84 Petersen JA, Straumann D, Weber KP: Clinical diagnosis of bilateral vestibular loss: three simple bedside tests. Ther Adv Neurol Disord 2013;6:41-45.

85 Kheradmand A, Zee DS: The bedside examination of the vestibulo-ocular reflex (VOR): an update. Rev Neurol (Paris) 2012;168:710-719.

86 Khasnis A, Gokula RM: Romberg's test. J Postgrad Med 2003;49:169-172.

87 Lanska DJ, Goetz CG: Romberg's sign: development, adoption, and adaptation in the 19th century. Neurology 2000;55:1201-1206.

$\$ 88$ Fujimoto C, Murofushi T, Chihara Y, Ushio M, Sugasawa K, Yamaguchi T, et al: Assessment of diagnostic accuracy of foam posturography for peripheral vestibular disorders: analysis of parameters related to visual and somatosensory dependence. Clin Neurophysiol 2009;120:1408-1414.

89 Szmulewicz DJ, McLean CA, MacDougall HG, Roberts L, Storey E, Halmagyi GM: CANVAS an update: clinical presentation, investigation and management. J Vestib Res 2014;24:465-474.

$\$ 90$ Halmagyi GM, Curthoys IS: A clinical sign of canal paresis. Arch Neurol 1988;45:737-739.

$\$ 91$ Migliaccio AA, Cremer PD: The 2D modified head impulse test: a 2D technique for measuring function in all six semi-circular canals. J Vestib Res 2011;21:227-234.

92 MacDougall HG, Weber KP, McGarvie LA, Halmagyi GM, Curthoys IS: The video head impulse test: diagnostic accuracy in peripheral vestibulopathy. Neurology 2009;73:1134-1141.

93 Mantokoudis G, Saber Tehrani AS, Kattah JC, Eibenberger K, Guede CI, Zee DS, et al: Quantifying the vestibuloocular reflex with video-oculography: nature and frequency of artifacts. Audiol Neurootol 2015;20:39-50. 
van de Berg et al.: Bilateral Vestibular Hypofunction: Challenges in Establishing the Diagnosis in Adults

-94 Weber KP, Aw ST, Todd MJ, McGarvie LA, Curthoys IS, Halmagyi GM: Head impulse test in unilateral vestibular loss: vestibulo-ocular reflex and catch-up saccades. Neurology 2008;70:454-463.

-95 Agrawal Y, Bremova T, Kremmyda 0, Strupp M: Semicircular canal, saccular and utricular function in patients with bilateral vestibulopathy: analysis based on etiology. J Neurol 2013;260:876-883.

-96 McGarvie LA, Curthoys IS, MacDougall HG, Halmagyi GM: What does the head impulse test versus caloric dissociation reveal about vestibular dysfunction in Ménière's disease? Ann NY Acad Sci 2015;1343:58-62.

-97 Aaronson NK, Müller M, Cohen PD, Essink-Bot ML, Fekkes M, Sanderman R, et al: Translation, validation, and norming of the Dutch language version of the SF-36 Health Survey in community and chronic disease populations. J Clin Epidemiol 1998;51:1055-1068.

98 Jacobson GP, Newman CW: The development of the Dizziness Handicap Inventory. Arch Otolaryngol Head Neck Surg 1990;116:424-427.

99 Tian JR, Shubayev I, Demer JL: Dynamic visual acuity during passive and self-generated transient head rotation in normal and unilaterally vestibulopathic humans. Exp Brain Res 2002;142:486-495.

100 Vital D, Hegemann SC, Straumann D, Bergamin O, Bockisch CJ, Angehrn D, et al: A new dynamic visual acuity test to assess peripheral vestibular function. Arch Otolaryngol Head Neck Surg 2010;136:686-691.

101 Fife TD, Tusa RJ, Furman JM, Zee DS, Frohman E, Baloh RW, et al: Assessment: vestibular testing techniques in adults and children: report of the Therapeutics and Technology Assessment Subcommittee of the American Academy of Neurology. Neurology 2000;55:1431-1441.

102 Herdman SJ, Tusa RJ, Blatt P, Suzuki A, Venuto PJ, Roberts D: Computerized dynamic visual acuity test in the assessment of vestibular deficits. Am J Otol 1998;19:790-796.

103 Furman J, Cass SP: Balance Disorders: A Case Study Approach. Philadelphia, Davis, 1996.

104 Hamid M: Measurements of the caloric response. Adv Audiol 1988;5:145-148.

105 Bárány R: Untersuchungen über den vom Vestibularapparat des Ohres reflectorisch ausgelösten rhythmischen Nystagmus und seine Begleiterscheinungen. Monatsschr Ohrenheilkd 1906;40:193-297.

106 Wit HP, Spoelstra HA, Segenhout JM: Bárány's theory is right, but incomplete. An experimental study in pigeons. Acta Otolaryngol 1990;110:1-6.

107 Wit HP, Segenhout JM: Caloric stimulation of the vestibular system of the pigeon under minimal influence of gravity. Acta Otolaryngol 1988;105:338-342.

108 Scherer H, Clarke AH: The caloric vestibular reaction in space. Physiological considerations. Acta Otolaryngol 1985;100:328-336.

109 Maes L, Dhooge I, De Vel E, D’Haenens W, Bockstael A, Vinck BM: Water irrigation versus air insufflation: a comparison of two caloric test protocols. Int J Audiol 2007;46:263-269.

110 Gonçalves DU, Felipe L, Lima TM: Interpretation and use of caloric testing. Braz J Otorhinolaryngol 2008;74: 440-446.

111 Souza JAC, Ganança CF, Segatin LA, Caovilla HH, Ganança MM: Limites normais dos parâmetros de avaliação à vectonistagmografia digital neurograff. Acta AWHO 2000;19:105.

112 Greven AJ, Oosterveld WJ, Rademakers WJ, Voorhoeve R: Caloric vestibular test with the use of air. Ann Otol Rhinol Laryngol 1979;88(1 pt 1):31-35.

113 Norré ME, Renier B: Inverted caloric nystagmus by warm air stimulation. Acta Otorhinolaryngol Belg 1979; 33:912-918.

114 Zangemeister WH, Bock O: Air versus water caloric test. Clin Otolaryngol Allied Sci 1980;5:379-387.

115 Coats AC: ENG examination technique. Ear Hear 1986;7:143-150.

116 Cooper JC Jr, Mason RL: Variability of air calorics vs water. Statistical implications. Arch Otolaryngol 1979;105: 113-115.

117 Greisen 0: Pseudocaloric nystagmus. Acta Otolaryngol 1972;73:341-343.

118 Möller C, Odkvist LM: The plasticity of compensatory eye movements in bilateral vestibular loss. A study with low and high frequency rotatory tests. Acta Otolaryngol 1989;108:345-354.

119 Barnes GR: Visual-vestibular interaction in the control of head and eye movement: the role of visual feedback and predictive mechanisms. Prog Neurobiol 1993;41:435-472.

120 Sills AW, Baloh RW, Honrubia V: Caloric testing 2. Results in normal subjects. Ann Otol Rhinol Laryngol Suppl 1977;86(5 pt 3 suppl 43):7-23.

121 Press SE, Goetzinger CP, Karlsen EA, Stevens JH: A study of five parameters of calorically-induced nystagmus in the clinical situation. J Aud Res 1979;19:127-135.

122 Karlsen EA, Mikhail HH, Norris CW, Hassanein RS: Comparison of responses to air, water, and closed-loop caloric irrigators. J Speech Hear Res 1992;35:186-191.

123 Bruner A, Norris TW: Age-related changes in caloric nystagmus. Acta Otolaryngol Suppl 1971;282:1-24.

124 Mulch G, Petermann W: Influence of age on results of vestibular function tests. Review of literature and presentation of caloric test results. Ann Otol Rhinol Laryngol Suppl 1979;88(2 pt 2 suppl 56):1-17.

125 Peterka RJ, Black FO, Schoenhoff MB: Age-related changes in human vestibulo-ocular reflexes: sinusoidal rotation and caloric tests. J Vestib Res 1990;1:49-59.

126 Mallinson AI, Longridge NS: Caloric response does not decline with age. J Vestib Res 2004;14:393-396.

127 Myers SF: Patterns of low-frequency rotational responses in bilateral caloric weakness patients. J Vestib Res 1992;2:123-131.

128 Eviatar A: The torsion swing as a vestibular test. Arch Otolaryngol 1970;92:437-444. 
van de Berg et al.: Bilateral Vestibular Hypofunction: Challenges in Establishing the Diagnosis in Adults

129 Baloh RW, Sills AW, Honrubia V: Impulsive and sinusoidal rotatory testing: a comparison with results of caloric testing. Laryngoscope 1979;89:646-654.

130 van de Berg R, Guinand N, Guyot JP, Kingma H, Stokroos RJ: The modified ampullar approach for vestibular implant surgery: feasibility and its first application in a human with a long-term vestibular loss. Front Neurol 2012;3:18.

131 Maes L, Dhooge I, De Vel E, D’Haenens W, Bockstael A, Keppler H, et al: Normative data and test-retest reliability of the sinusoidal harmonic acceleration test, pseudorandom rotation test and velocity step test. J Vestib Res 2008;18:197-208.

132 Möller C, Odkvist L, White V, Cyr D: The plasticity of compensatory eye movements in rotatory tests. I. The effect of alertness and eye closure. Acta Otolaryngol 1990;109:15-24.

133 Wall C 3rd, Black FO, Hunt AE: Effects of age, sex and stimulus parameters upon vestibulo-ocular responses to sinusoidal rotation. Acta Otolaryngol 1984;98:270-278.

134 Henry DF, DiBartolomeo JD: Closed-loop caloric, harmonic acceleration and active head rotation tests: norms and reliability. Otolaryngol Head Neck Surg 1993;109:975-987.

135 Li CW, Hooper RE, Cousins VC: Sinusoidal harmonic acceleration testing in normal humans. Laryngoscope 1991;101:192-196.

136 Su YY, Chiou WY, Weng PK, Wang HW: Computerized rotational vestibular testing in normal subjects. Zhonghua Yi Xue Za Zhi (Taipei) 2000;63:377-383.

137 Leigh RJ: What is the vestibulo-ocular reflex and why do we need it? In Baloh RW, Halmagyi GM (eds): Disorders of the Vestibular System. New York, Oxford University Press, 1996, pp 12-19.

138 Leigh RJ, Sawyer RN, Grant MP, Seidman SH: High-frequency vestibuloocular reflex as a diagnostic tool. Ann NY Acad Sci 1992;656:305-314.

139 van de Berg R, Guinand N, Nguyen TA, Ranieri M, Cavuscens S, Guyot JP, et al: The vestibular implant: frequencydependency of the electrically evoked vestibulo-ocular reflex in humans. Front Syst Neurosci 2014;8:255.

140 Bouveresse A, Kalfane K, Gentine A, Eichhorn JL, Kopp C: Pseudorandom rotational stimuli of the vestibuloocular reflex in humans: normal values of the transfer function. Acta Otorhinolaryngol Belg 1998;52:207-214.

141 Jenkins HA, Goldberg J: Test-retest reliability of the rotatory test in normal subjects. Adv Otorhinolaryngol 1988;41:190-195.

142 Wolfe JW, Engelken EJ, Kos CM: Low-frequency harmonic acceleration as a test of labyrinthine function: basic methods and illustrative cases. ORL 1977;86:130-142.

143 Furman JM, Kamerer DB: Rotational responses in patients with bilateral caloric reduction. Acta Otolaryngol 1989;108:355-361.

144 Perez Fornos A, Guinand N, van de Berg R, Stokroos R, Micera S, Kingma H, et al: Artificial balance: restoration of the vestibulo-ocular reflex in humans with a prototype vestibular neuroprosthesis. Front Neurol 2014;5:66.

145 Clark KF: Torsion swing chair. Ear Hear 1986;7:191-197.

146 Curthoys IS: A critical review of the neurophysiological evidence underlying clinical vestibular testing using sound, vibration and galvanic stimuli. Clin Neurophysiol 2010;121:132-144.

147 Iwasaki S, McGarvie LA, Halmagyi GM, Burgess AM, Kim J, Colebatch JG, et al: Head taps evoke a crossed vestibulo-ocular reflex. Neurology 2007;68:1227-1229.

148 Colebatch JG, Rothwell JC: Motor unit excitability changes mediating vestibulocollic reflexes in the sternocleidomastoid muscle. Clin Neurophysiol 2004;115:2567-2573.

149 Curthoys IS, Vulovic V: Vestibular primary afferent responses to sound and vibration in the guinea pig. Exp Brain Res 2011;210:347-352.

150 Rosengren SM, Welgampola MS, Colebatch JG: Vestibular evoked myogenic potentials: past, present and future. Clin Neurophysiol 2010;121:636-651.

151 Todd NP, Rosengren SM, Aw ST, Colebatch JG: Ocular vestibular evoked myogenic potentials (OVEMPs) produced by air- and bone-conducted sound. Clin Neurophysiol 2007;118:381-390.

152 Papathanasiou ES, Murofushi T, Akin FW, Colebatch JG: International guidelines for the clinical application of cervical vestibular evoked myogenic potentials: an expert consensus report. Clin Neurophysiol 2014;125: 658-666.

153 Li C, Layman AJ, Carey JP, Agrawal Y: Epidemiology of vestibular evoked myogenic potentials: data from the Baltimore Longitudinal Study of Aging. Clin Neurophysiol 2015, Epub ahead of print.

154 Welgampola MS, Colebatch JG: Vestibulocollic reflexes: normal values and the effect of age. Clin Neurophysiol 2001;112:1971-1979.

155 Taylor RL, Wijewardene AA, Gibson WP, Black DA, Halmagyi GM, Welgampola MS: The vestibular evokedpotential profile of Ménière's disease. Clin Neurophysiol 2011;122:1256-1263.

156 Lin MY, Timmer FC, Oriel BS, Zhou G, Guinan JJ, Kujawa SG, et al: Vestibular evoked myogenic potentials (VEMP) can detect asymptomatic saccular hydrops. Laryngoscope 2006;116:987-992.

157 Singh NK, Barman A: Characterizing the frequency tuning properties of air-conduction ocular vestibular evoked myogenic potentials in healthy individuals. Int J Audiol 2013;52:849-854.

158 McCaslin DL, Jacobson GP, Hatton K, Fowler AP, DeLong AP: The effects of amplitude normalization and EMG targets on cVEMP interaural amplitude asymmetry. Ear Hear 2013;34:482-490.

159 Rauch SD, Zhou G, Kujawa SG, Guinan JJ, Herrmann BS: Vestibular evoked myogenic potentials show altered tuning in patients with Ménière’s disease. Otol Neurotol 2004;25:333-338. 
van de Berg et al.: Bilateral Vestibular Hypofunction: Challenges in Establishing the Diagnosis in Adults

160 van Tilburg MJ, Herrmann BS, Guinan JJ Jr, Rauch SD: Normalization reduces intersubject variability in cervical vestibular evoked myogenic potentials. Otol Neurotol 2014;35:e222-e227.

161 Winters SM, Berg IT, Grolman W, Klis SF: Ocular vestibular evoked myogenic potentials: frequency tuning to air-conducted acoustic stimuli in healthy subjects and Ménière's disease. Audiol Neurootol 2012;17:12-19.

162 Funabashi M, Santos-Pontelli TE, Colafemina JF, Pavan TZ, Carneiro AA, Takayanagui OM: A new method to analyze the subjective visual vertical in patients with bilateral vestibular dysfunction. Clinics 2012;67:11271131.

163 Brantberg K, Löfqvist L: Preserved vestibular evoked myogenic potentials (VEMP) in some patients with walking-induced oscillopsia due to bilateral vestibulopathy. J Vestib Res 2007;17:33-38.

164 Richtlijn: diagnostiek en behandeling van het obstructieveslaapapneusyndroom bij volwassenen. 's-Hertogenbosch, Nederlandse Vereniging van Artsen voor Longziekten en Tuberculose, 2009.

165 Staab JP, Rohe DE, Eggers SD, Shepard NT: Anxious, introverted personality traits in patients with chronic subjective dizziness. J Psychosom Res 2014;76:80-83.

166 Fridman GY, Della Santina CC: Progress toward development of a multichannel vestibular prosthesis for treatment of bilateral vestibular deficiency. Anat Rec (Hoboken) 2012;295:2010-2029.

167 Golub JS, Ling L, Nie K, Nowack A, Shepherd SJ, Bierer SM, et al: Prosthetic implantation of the human vestibular system. Otol Neurotol 2014;35:136-147.

168 Lewis RF, Haburcakova C, Gong W, Lee D, Wall C 3rd, Thompson L, et al: Vestibular prosthesis tested in rhesus monkeys. Conf Proc IEEE Eng Med Biol Soc 2011;2011:2277-2279. 